\title{
Variations in Physiological, Psychomotor, and Analgesic Parameters during Titration of Nitrous Oxide in 3-12 Years Old Children Managed with Inhalation Sedation
}

\author{
Shivangi Sharma ${ }^{1}$, Radhika Chopra ${ }^{2}$, Shivani Mathur ${ }^{3}$, Vinod Sachdev ${ }^{4}$, Kunal Gupta ${ }^{5}$
}

\begin{abstract}
Background: The present study was designed to assess variations in physiological, psychomotor parameters, and analgesic effects at various levels of nitrous oxide-oxygen analgesia in 3-12 years old children.

Design: One hundred children aged 3-12 years were assessed for physiological, psychomotor, and analgesic parameters at various concentrations of $\mathrm{N}_{2} \mathrm{O}$, i.e., baseline, $20,40,50$, and $0 \%\left(100 \% \mathrm{O}_{2}\right)$. Physiological, psychomotor, and analgesic effects were assessed using a pulse oximeter, bender visual-motor Gestalt test, and response to electric pulp tester, respectively.

Results: Oxygen saturation $\left(\mathrm{SpO}_{2}\right)$ showed a significant increase while heart rate (HR) showed a significant reduction at $50 \% \mathrm{~N}_{2} \mathrm{O}$. No significant changes were observed in respiratory rate with a change in $\mathrm{N}_{2} \mathrm{O}$ levels. Significant reduction in the pain scores was found at the same level of stimulation by an electric pulp tester at 40 and $50 \%$ levels. The psychomotor changes were consistently higher at every concentration of nitrous oxide. However, no correlation could be found between various parameters tested.

Conclusion: $\mathrm{N}_{2} \mathrm{O}$ caused a significant increase in $\mathrm{SpO}_{2}$ in both the age groups, a decrease in $\mathrm{HR}$, a significant decrease in pain score at 40 and $50 \%$ concentration of $\mathrm{N}_{2} \mathrm{O}$, and had a significant effect on the psychomotor ability of children.

Keywords: Analgesic parameter, Nitrous oxide, Physiological parameter, Psychomotor parameter.

International Journal of Clinical Pediatric Dentistry (2020): 10.5005/jp-journals-10005-1852
\end{abstract}

\section{INTRODUCTION}

The clinical management of children in the dental office has always remained a challenge for the clinicians. With the current changes in parenting and minimum coping skills of children, the use of pharmacological means is gaining popularity. Nitrous oxide analgesia is one of the most popular adjuncts to behavior management for children. ${ }^{1}$

Since its recognition in past decades, nitrous oxide $\left(\mathrm{N}_{2} \mathrm{O}\right)$ has been used widely to relieve pain and anxiety relief for patients undergoing surgical procedures. ${ }^{2}$ The American Academy of Pediatric Dentistry (AAPD) recognizes relative analgesia (RA) using nitrous oxide $\left(\mathrm{N}_{2} \mathrm{O}\right)$ oxygen analgesia as a safe and effective technique to reduce anxiety, produce analgesia, and results in enhancing effective communication between patients and doctors. ${ }^{3} \mathrm{~N}_{2} \mathrm{O}$ produces non-specific central nervous system (CNS) depression sufficient to produce moderate analgesia. When administered in concentration between 20 and $50 \%$, the patient remains awake but calm and can follow verbal instructions. ${ }^{4}$

Acute and chronic adverse events of $\mathrm{N}_{2} \mathrm{O}$ are rare when used with $\mathrm{O}_{2}$. Some adverse effects that may be witnessed are nausea, vomiting, sense of detachment, headache, hiccups, and double vision. The most common adverse events reported in the literature are nausea and vomiting occurring in $0.5 \%$ of patients. ${ }^{5}$

Hypoxemia is one of the side effects of nitrous oxide-oxygen analgesia and is usually found when $\mathrm{N}_{2} \mathrm{O}$ concentration is higher than $70 \%$ or when it falls to zero at the end of operation when $100 \%$ $\mathrm{O}_{2}$ is inhaled. The maximum concentration of $\mathrm{N}_{2} \mathrm{O}$ suggested for dental operations has been $55 \%$ in which there was no chance for hypoxemia. ${ }^{6-9}$

\footnotetext{
${ }^{1-4}$ Department of Pedodontics and Preventive Dentistry, ITS Centre for Dental Studies and Research, Muradnagar, Uttar Pradesh, India

${ }^{5}$ Children Dental Centre, Gurugram, Haryana, India
}

Corresponding Author: Radhika Chopra, Department of Pedodontics and Preventive Dentistry, ITS Centre for Dental Studies and Research, Muradnagar, Uttar Pradesh, India, Phone: +91 8800977945, e-mail: drradhikachopra@gmail.com

How to cite this article: Sharma S, Chopra R, Mathur S, et al. Variations in Physiological, Psychomotor, and Analgesic Parameters during Titration of Nitrous Oxide in 3-12 Years Old Children Managed with Inhalation Sedation. Int J Clin Pediatr Dent 2020;13(6):650-655.

Source of support: Nil

Conflict of interest: None

Various studies have also supported the safety of nitrous oxideoxygen analgesia in patients of American Society of Anesthesiology (ASA) classes I and II. ${ }^{6,10}$

Use of appropriate technique and titration to the exact level is required for appropriate analgesia. Most patients achieve this endpoint at $\mathrm{N}_{2} \mathrm{O}$ concentrations $<50 \%$. If the patient requires a percentage higher than $50 \%$, then the operator should get alert to the fact that the cumulative effects of the drug may quickly change the level of sedation. As the dose of $\mathrm{N}_{2} \mathrm{O}$ is not age or weight-related so slow titration of small doses of the drug is important to prevent over sedation. ${ }^{5}$

Limited literature is available on changes in physiological, psychomotor, and analgesic parameters with each increment of $\mathrm{N}_{2} \mathrm{O}$ level in the younger age group. Houpt et al. measured the psychomotor ability of children aged 4 to 13 years at $50 \% \mathrm{~N}_{2} \mathrm{O}$ 
and found that there were appreciable signs and symptoms of nitrous oxide conscious sedation in children. ${ }^{11}$ However, there is no information available in the literature regarding the changes in psychomotor ability at each increment during titration of $\mathrm{N}_{2} \mathrm{O}$ and whether these changes can be correlated with the analgesic effects of $\mathrm{N}_{2} \mathrm{O}$.

Thus, this study was planned to assess the variation in physiological, psychomotor parameters, and analgesic effects during sedation with increasing concentrations of nitrous oxide in children aged 3-12 years and to evaluate any correlation between these parameters.

\section{Materials and Methods}

\section{Study Design and Ethical Approval}

This study was approved by the I.T.S. Centre for Dental Studies and Research, Muradnagar Institutional Review Board.

The sample of 100 children aged 3-12 years indicated for dental treatment under nitrous oxide-oxygen analgesia was selected for the study. Selection criteria included:

- The patient indicated for any treatment under nitrous oxideoxygen analgesia.

- The capability to draw at least one figure on the psychomotor evaluation component.

- No sensory or cognitive impairment or any medically compromising condition.

Children were treated in the Department of Pedodontics and Preventive Dentistry (I.T.S. Centre for Dental Studies and Research, Muradnagar) and Children's Dental Center, Gurugram.

Each child participated in only one session in this study. After consent to participate in the study was obtained from their parents, the selected children were given nitrous oxide-oxygen analgesia as part of the standard procedure, as determined by the individual practitioner providing the dental treatment. Patients were asked to fast for 2 hours before the appointment. The physiological, psychomotor, and analgesic parameters were assessed before starting the procedure. After confirming again for the inclusion criteria, administration of $100 \%$ oxygen through the appropriate selected nasal hood was delivered. Then, procedure for titration of $\mathrm{N}_{2} \mathrm{O}$ was started where initially $20 \% \mathrm{~N}_{2} \mathrm{O}$ was delivered for one minute followed by an increment of $10 \% \mathrm{~N}_{2} \mathrm{O}$ every 1 minute. All the parameters were recorded at baseline, 20,40, and $50 \% \mathrm{~N}_{2} \mathrm{O}$ levels by an independent observer. The required clinical procedure was performed at the appropriate $\mathrm{N}_{2} \mathrm{O}$ level for each patient. After completion of the procedure, $100 \%$ oxygen $\left(\mathrm{O}_{2}\right)$ was delivered for three minutes and all the parameters were recorded again.

\section{Physiological Parameters}

Oxygen saturation $\left(\mathrm{SpO}_{2}\right)$ and heart rate $(\mathrm{HR})$ were measured by using a pulse oximeter. Respiratory rate (RR) was measured by observing inflation and deflation of reservoir bag.

\section{Analgesic Effects}

Analgesic effects were measured by initially recording the reading of the electronic pulp tester at which the patient responded to sensitivity on maxillary deciduous canine at the baseline. The maxillary deciduous canine was selected because it was the common tooth in all the age groups. The patient was then exposed to the same level of electric stimulation on the same tooth at each concentration level of $\mathrm{N}_{2} \mathrm{O}$. Sound eyes motor scale (SEM scale) was used to score the response of the patient to electric stimulation at every step of $\mathrm{N}_{2} \mathrm{O}$ titration.

\section{Psychological Parameters}

To determine the psychomotor effects at different concentrations, BENDER VISUAL MOTOR GESTALT TEST (Fig. 1) was used in which the child was asked to draw one of the figures from the given chart. The recordings were done based on the quality of the figure according to the scoring criteria at each level of titration. The number of errors was calculated from the scoring for each level. An independent observer previously calibrated for all the parameters was responsible for recording all the scores. Blinding could be done only for the Bender Visual Motor Gestalt test as the drawings were later evaluated. All other recordings were done at the time of titration.

\section{Statistical Analysis}

All the data were collected and entered in MS Excel and analyzed using SPSS 16.0 for windows (SPSS Inc., Chicago, IL, USA, 2001). The normality of data was tested by the Shapiro-Wilks test. Descriptive statistics, frequency distribution, including the mean, median, and SD were calculated for all measurements. Intergroup comparison for normal data was tested by independent $t$-test, and intragroup comparison was tested by paired $t$-test (parametric test) and for skewed data like scores for intergroup comparison by a non-parametric test, Mann-Whitney $U$ test and for intragroup comparison Wilcoxon signed-rank test was used. The qualitative data association was tested by the Pearson Chi-square test. Multivariate linear regression analysis was also done.

\section{RESULTS}

This study was conducted on a sample of 100 children in the age range of 3-12 years (mean age $=6.78$ years) indicated for dental treatment under nitrous oxide sedation. There were 40 males and 60 females in the study. Children were divided into two groups:

Group I (3-6 years): No. of children $(n=48)(m=22, f=26)$ mean age $=4.917$ years.

Triangle
1. Three clearly defined sides
2. One corner higher than others
A
Open square and circle
1. No more than slight separation of forms
2. No major distortions or circle or open square
3. Circle and two cornered sauare fairly equal size
B
Three lines cross
1. Three continuous, intersecting lines
2. Intersection fairly accurate
3. One horizontal and two diagonals
C
Directional arrows
1. Absence of reversed for :floating: tips
2. Sharp points on tips'
3. No indication of directional confusion
4. Fairly equal length of "legs"
D

Fig. 1: Evaluation of psychomotor effects by Bender Visual Motor Gestalt Test 
Group II (7-12 years): No. of children $(n=52)(m=18, f=34)$ mean age $=8.542$ years.

The results of the present investigations have been evaluated under the following headings:

\section{Analysis of Physiological Parameters with Respect to Various Concentration of Nitrous Oxide in the Different Age Groups}

A paired $t$-test was carried out to compare the hemoglobin oxygen saturation, $H R$, and $R R$ values at various concentrations of nitrous oxide and oxygen $\left(\mathrm{N}_{2} \mathrm{O}\right)$.

\section{Hemoglobin Saturation}

There was an increase in the mean value of oxygen saturation from baseline to $20 \% \mathrm{~N}_{2} \mathrm{O}(p<0.001)$ and also while comparing the values from baseline to $100 \% \mathrm{O}_{2}(p<0.001)$ and similar results were found for both the age groups. Figure 2 shows the line diagram depicts an initial increase in $\mathrm{SpO}_{2}$ levels from baseline to $20 \% \mathrm{~N}_{2} \mathrm{O}$ which then remains at a similar level for the rest of the $\mathrm{N}_{2} \mathrm{O}$ concentration levels.

\section{Heart Rate}

There was a significant difference between HR from baseline to $100 \% \mathrm{O}_{2}(p=0.003$, i.e., $p<0.05)$. However, when the two age groups were analyzed separately, significant differences were found in the 3-6years age group between baseline vs $50 \% \mathrm{~N}_{2} \mathrm{O}(p=0.028)$ and baseline vs $100 \% \mathrm{O}_{2}(p=0.018)$. On the contrary, no significant differences were found in the 7-12 years age group. Figure 3 shows the line diagram of means of the HR which depicts the significant decrease in HR in 3-6 years age group throughout the procedure and after the recovery period HR returned to normal whereas, in 7-12 years age group, there was a statistically insignificant increase in $\mathrm{HR}$ at $20 \% \mathrm{~N}_{2} \mathrm{O}(p=0.891, p>0.005)$ followed by a decrease in $\mathrm{HR}$ at $40 \% \mathrm{~N}_{2} \mathrm{O}(p=0.576, p>0.05)$ which returned to normal after the recovery period.

\section{Respiratory Rate}

There was no significant difference in the RR with different concentrations of $\mathrm{N}_{2} \mathrm{O}$ for 100 patients. Similar trends were found for the RRs when both age groups were analyzed separately. Figure 4 shows the line diagram depicting no change in RR with changes in $\mathrm{N}_{2} \mathrm{O}$ concentrations. However, the RR was generally higher for the 3-6 years age group.

\section{Analysis of Analgesic Parameters with Respect to Various Concentrations of Nitrous Oxide in Different Age Groups}

The analysis depicts the comparison of means of SEM values at different concentrations of $\mathrm{N}_{2} \mathrm{O}$ and $\mathrm{O}_{2}$. A significant decrease in SEM scores was found at $40 \% \mathrm{~N}_{2} \mathrm{O}(p=0.020)$ which then increased at $100 \% \mathrm{O}_{2}(p=0.033)$. When the age groups were analyzed separately, significant differences were found at baseline vs $40 \%$ $\mathrm{N}_{2} \mathrm{O}$ (i.e., $p=0.025$ for $3-6$ years, $p=0.005$ for $7-12$ years) and at baseline $v s 50 \% \mathrm{~N}_{2} \mathrm{O}$ ( $p=0.025$ for $3-6$ years and $p=0.024$ for $7-12$ years). Figure 5 shows the means of SEM scores which depict that there was a decrease in SEM scoring for both the age groups at $40-50 \% \mathrm{~N}_{2} \mathrm{O}$ levels.

\section{Analysis of Psychomotor Parameters with Respect to Various Concentrations of Nitrous Oxide in Different Age Groups}

This analysis indicates the mean number of errors done by subjects at various concentrations of $\mathrm{N}_{2} \mathrm{O}$ and $\mathrm{O}_{2}$ in different age groups. In both age groups, highly significant differences were found between various concentrations of $\mathrm{N}_{2} \mathrm{O}$ for psychomotor parameters ( $p$ $<0.001$ ). Figure 6 shows the means of no. of errors which has consistently increased with an increase in the concentration of nitrous oxide.

Association of different parameters with age and concentration through regression analysis Table 1 presents a multivariate stepwise linear regression analysis of all parameters. The mean score of $\mathrm{SpO}_{2}, \mathrm{HR}, \mathrm{RR}, \mathrm{SEM}$, and psychomotor parameters retained a significant positive association with age in children aged 3 to 6 years. Significant association in 7-12 years old children was found only in-between $\mathrm{SpO}_{2}$ and SEM. Also, there was a weak correlation between psychomotor and analgesic parameters when SEM baseline, $20 \% \mathrm{~N}_{2} \mathrm{O}, 40 \% \mathrm{~N}_{2} \mathrm{O}, 50 \% \mathrm{~N}_{2} \mathrm{O}$, and $100 \% \mathrm{O}_{2}$ was compared to all concentrations of psychomotor parameters. The results were statistically insignificant when correlation coefficients were analyzed.

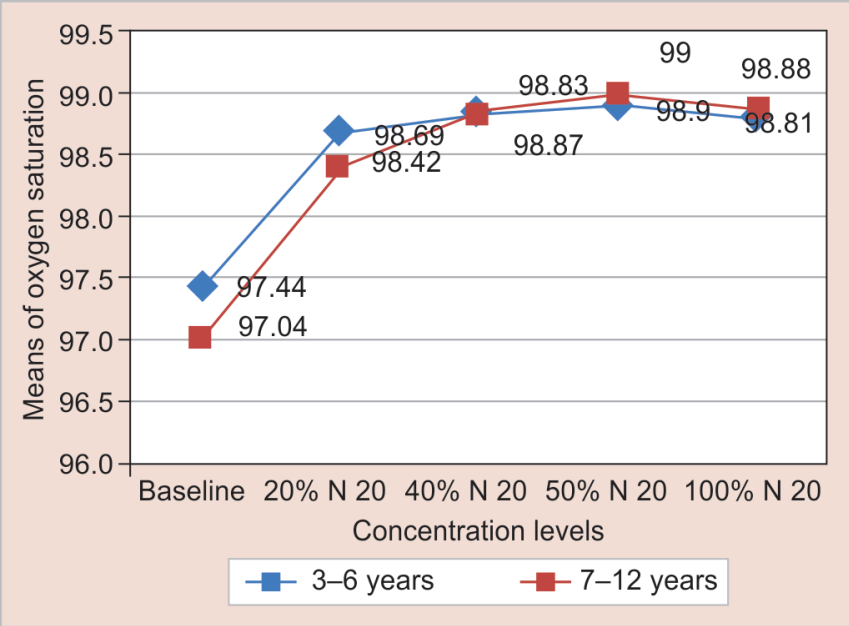

Fig. 2: Graph showing the means of oxygen saturation $\left(\mathrm{SpO}_{2}\right)$ at different concentrations of $\mathrm{N}_{2} \mathrm{O}$ in different age groups

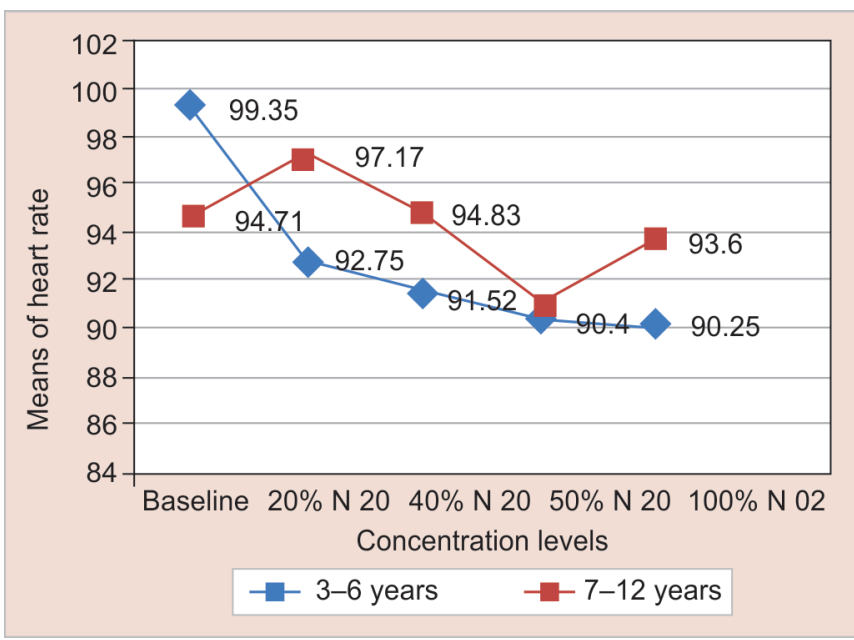

Fig. 3: Graph showing the means of heart rates at different concentrations of nitrous oxide in different age groups 


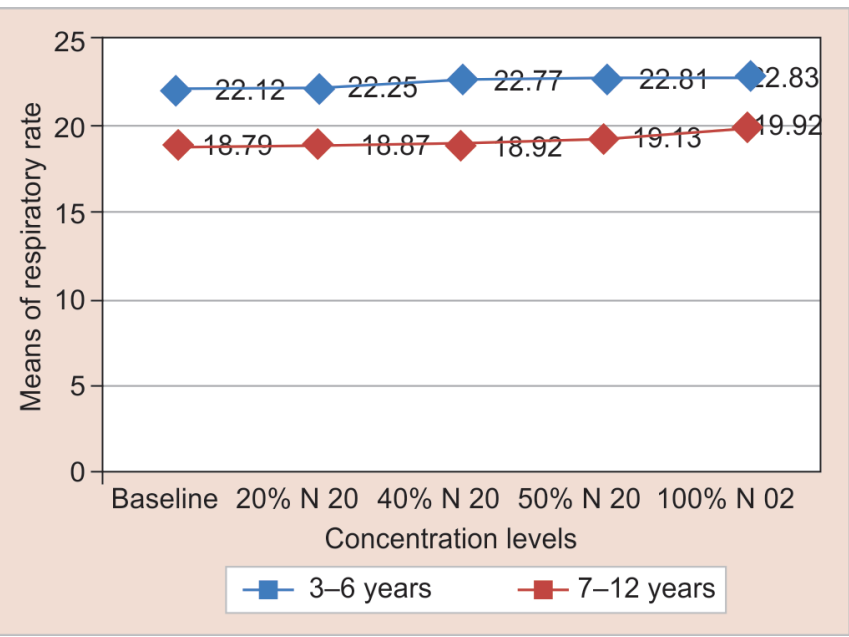

Fig. 4: Graph showing the means of the respiratory rate at different concentrations of nitrous oxide in different age groups

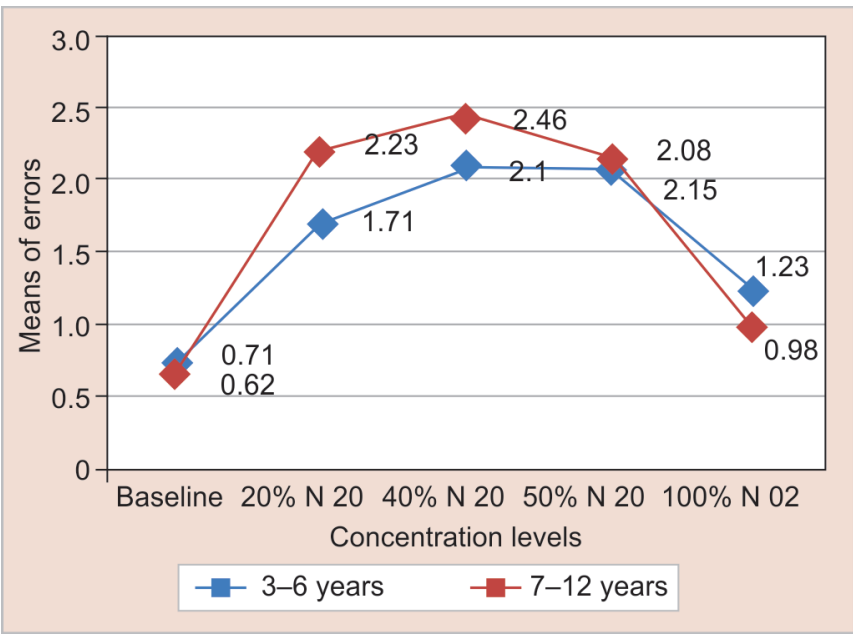

Fig. 6: Graph showing the means of no. of errors at different concentrations of $\mathrm{N}_{2} \mathrm{O}$ in different age groups

\section{Discussion}

$\mathrm{N}_{2} \mathrm{O}$ is an analgesic and sedative drug that is administered in the gaseous state via the respiratory system. With a safety record of over 160 years, nitrous oxide-oxygen analgesia is now an indivisible part of the dental setups in North America, Europe Australia, and many parts of Asia. However, in some developing countries, there is still an imaginary picture of the use of nitrous oxide in private dental practice. A study by Vilanova-Saingery et al. conducted in Brazil, showed that the majority of practitioners had a strong opinion of $\mathrm{N}_{2} \mathrm{O}$, although $40 \%$ did not. ${ }^{12}$ In countries like India, the "smokescreen" surrounding this technique has begun to dissolute and nitrous oxide analgesia has started gaining interest among the private dental practioneers. ${ }^{13}$ There had been studies on physiological changes regarding nitrous oxide-oxygen analgesia in older age groups but it has now become a necessity to investigate the effects of nitrous oxide in children as young as 3 years of age.

The findings of this study showed that nitrous oxide caused a remarkable increase in oxygen saturation in both age groups. $\mathrm{SpO}_{2}$ hovered consistently at $98 \%$ throughout the sedation. As

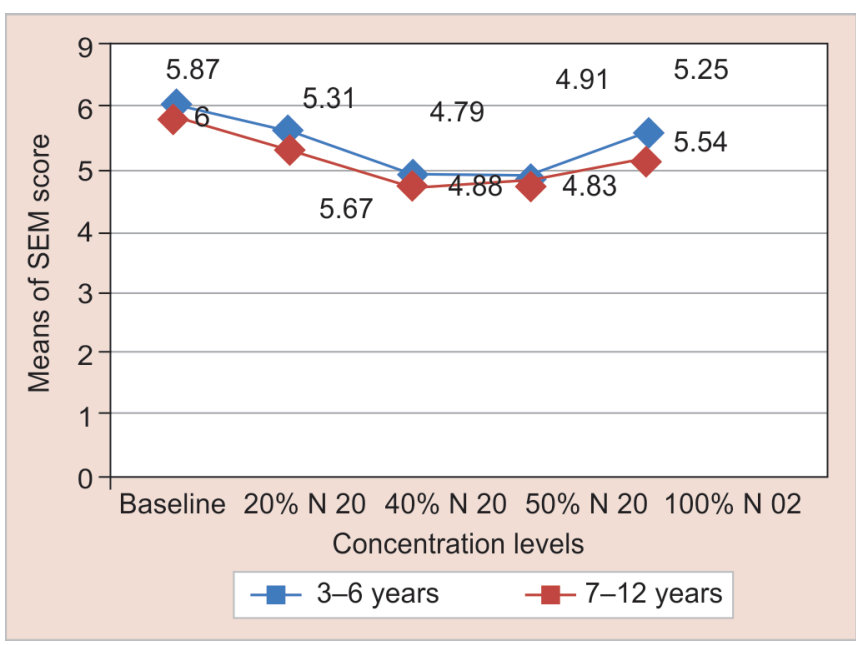

Fig. 5: Graph showing the means of SEM scores at different concentrations of $\mathrm{N}_{2} \mathrm{O}$ in different age groups

the patient was breathing $100 \%$ oxygen post sedation, the post sedation $\mathrm{SpO}_{2}$ measurement was higher than preoperative $\mathrm{SpO}_{2}$. Furthermore, while titrating the concentration from baseline to a higher concentration of $\mathrm{N}_{2} \mathrm{O}, \mathrm{SpO}_{2}$ was slightly greater because $80 \%$ oxygen was being delivered to the patient during the procedure which is more than physiological atmospheric oxygen (21\%). The findings of the present study concur with the findings of Frumin and Edelist who found that alveolar dilution caused by $\mathrm{N}_{2} \mathrm{O}$ diffusion in healthy patients produced clinically insignificant changes in $\mathrm{SpO}_{2}$ and concluded that diffusion hypoxia might not occur clinically. ${ }^{14}$ Also, a study conducted by Khinda et al. proved that the clinical occurrence of diffusion hypoxia is not possible while following the daily procedure of nitrous oxide sedation. ${ }^{15}$

There was a significant decrease in HR for the 3-6 years age group which does not risk the safety of the procedure and was well within the normal range. A slight depressing effect on myocardial contractility has been reported with $\mathrm{N}_{2} \mathrm{O}$, but $\mathrm{N}_{2} \mathrm{O}$ in a therapeutic range used in dentistry has no known effect on $\mathrm{HR}$ or cardiac output. More likely, the observed mean physiological parameters during $\mathrm{N}_{2} \mathrm{O}$ conditions would not be attributed to direct cardiovascular depression, but greater patient relaxation. ${ }^{16}$ Similar results were detected by Hogue, Primosch, Allison, Nathan, Mueller, and Major. ${ }^{17-19}$ In contrast, Roberts et al. found a light pulse increase 10 minutes after starting the procedure, coexisting with the administration of local anesthesia and after the dental treatment performed in children. ${ }^{20}$ The remarkable pulse decrease could be considered as a sign related to sedation, but not characteristic of the desired sedation level, as it decreases progressively even through oxygenation. Howard in 1997 also examined that nitrous oxideoxygen inhalation even at $10 \% \mathrm{~N}_{2} \mathrm{O}$, had been shown to reduce significantly the HR during local anesthetic delivery. The same study showed that the HR decreased during the operative phase of treatment, but only with concentrations at $50 \%$ nitrous oxide. ${ }^{21}$

Respiratory rate was slightly increased throughout the procedure for all the patients but the increase was statistically insignificant. As most of the inhalation agents tend to increase RR but decrease tidal volume and produce a dose-dependent reduction in mean arterial pressure, $\mathrm{N}_{2} \mathrm{O}$ is distinguished from other agents in that it does not reduce net ventilation or produce any change in arterial pressure. ${ }^{22} \mathrm{~A}$ study by Brondani et al. supported 
Table 1: Multivariate linear regression analysis for prediction of dependent factors $\mathrm{SpO}_{2}, \mathrm{HR}, \mathrm{RR}$, SEM, and error with age and concentration as independent factors for two age groups

\begin{tabular}{|c|c|c|c|c|c|c|}
\hline \multicolumn{7}{|c|}{ 3-6 years } \\
\hline & $\begin{array}{l}\text { Dependent varial } \\
\mathrm{SpO}_{2}\end{array}$ & & $\begin{array}{l}\text { Dependent variable: } \\
H R\end{array}$ & $\begin{array}{l}\text { Dependent variable: } \\
R R\end{array}$ & $\begin{array}{l}\text { Dependent variable: } \\
\text { SEM }\end{array}$ & $\begin{array}{l}\text { Dependent } \\
\text { variable: error }\end{array}$ \\
\hline Independent variables & Reg. coefficient & & Reg. coefficient & Reg. coefficient & Reg. coefficient & Reg. coefficient \\
\hline (Constant) & $97.490^{*}$ & & $104.237^{*}$ & $18.481^{*}$ & $6.388^{*}$ & $0.827^{*}$ \\
\hline CONC & $0.296^{*}$ & & -2.056 & 2179.404 & $-0.171^{*}$ & $0.142^{*}$ \\
\hline AGE & $0.032^{\mathrm{NS}}$ & & $-1.061^{\mathrm{NS}}$ & $2197.885^{\text {NS }}$ & $-0.099^{\mathrm{NS}}$ & $0.064^{\mathrm{NS}}$ \\
\hline \multicolumn{7}{|c|}{$7-12$ years } \\
\hline (Constant) & $96.826^{*}$ & $98.069^{*}$ & & $17.366^{*}$ & $6.360^{*}$ & $1.875^{*}$ \\
\hline CONC & $0.425^{*}$ & $-0.819^{\mathrm{NS}}$ & & $0.256^{\mathrm{NS}}$ & $-0.160^{*}$ & $0.065^{\mathrm{NS}}$ \\
\hline AGE & $0.040^{\mathrm{NS}}$ & $-0.154^{\mathrm{NS}}$ & & $0.117^{\mathrm{NS}}$ & $-0.076^{\mathrm{NS}}$ & $-0.045^{\mathrm{NS}}$ \\
\hline
\end{tabular}

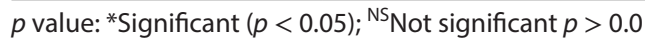

this fact regarding the relationship between psychoactive drugs and $\mathrm{N}_{2} \mathrm{O}$ which indicated that there were no alterations in the RR, a finding which supported the clinical safety of the concomitant use of $\mathrm{N}_{2} \mathrm{O}$ among pediatric patients. As stated in the literature, $\mathrm{N}_{2} \mathrm{O}$ may selectively affect the cerebral cortex and, therefore, does not depress the respiratory centers located in the bulb. ${ }^{23}$ Also, in our study, RR was slightly higher in the younger age group as compared to the older ones which is a normal physiological variation for the respective age groups.

In our study, there was a remarkable reduction in the SEM scores for the same level of stimulation by an electric pulp vitalometer at 40 and $50 \% \mathrm{~N}_{2} \mathrm{O}$ levels. $\mathrm{N}_{2} \mathrm{O}$ analgesia works by anxiolysis that allows the patient to tolerate troublesome procedures by reducing discomfort, thereby expediting the delivery of procedures. ${ }^{24}$ Grønbæk et al. found that $\mathrm{N}_{2} \mathrm{O} / \mathrm{O}_{2}$ inhalation increases reaction time, but has no effect on pulpal sensitivity. It reduces pressure-induced muscle pain, but this effect can to some extent be explained as due to a delayed reaction caused by the sedative effect of the drug. Emmanouil et al. also reviewed the safety and efficacy of $\mathrm{N}_{2} \mathrm{O}$ and found it to be effective during a brief, but mild to moderately painful pediatric procedures. ${ }^{25}$

Several studies in the literature have used a visual analog scale (VAS) in which children rate their pain at the end of the procedure. However, owing to its subjective nature; this can be inconsistent in children especially after an episode of sedation. In the present study, the SEM scale in response to the electric pulp vitalometer was used because it is an objective criterion in which the sensation of pain generates in the patient's eyes, bodily movements, and verbal expressions of discomfort. Electric pulp tester was used to produce the sensation of pain score as it was easily reproducible. ${ }^{26}$

In addition, $\mathrm{N}_{2} \mathrm{O}$ has a significant effect on the psychomotor ability of children, thus affecting their sense of experiencing the discomfort of clinical situations. There was a significant difference in the no. of errors in both age groups. The psychomotor effects could be appreciated at even the lower concentrations of $\mathrm{N}_{2} \mathrm{O}$ and overall, the mean number of errors was consistently higher with nitrous oxide than without. These findings are in agreement with Trieger and his colleagues who demonstrated that nitrous oxideoxygen combinations of 25,50 , and $70 \%$ affected psychomotor functioning as measured by the use of a modified Bender Motor Gestalt drawing test but the observed effects were rapidly reversed following cessation of the nitrous oxide. ${ }^{5,27}$ Many investigators have attempted to measure the degree of psychomotor impairment preoperatively and at given periods postoperatively following the administration of nitrous oxide, usually in combination with other inhalation anesthetic agents or intravenously administered drugs. These studies have demonstrated that psychomotor impairments are accruing from the administration of these agents and that they diminish over time. ${ }^{28}$

However, no correlations could be established between the psychomotor and analgesic parameters in our study, thus emphasizing the fact that it is difficult to establish objective criteria to assess the best level of $\mathrm{N}_{2} \mathrm{O}$ titration for a patient for maximum clinical advantage. It is the clinical judgment of the operator and subjective signs of the patient which can effectively assess the most appropriate level of sedation for performing a clinical procedure. One of the strengths of this study was to examine the physiological changes, the psychomotor, and analgesic effects as well as the correlation between these parameters for the younger age group. The results of our work showed that the pain experienced by subjects was higher when they were no longer under nitrous oxide effects.

\section{Limitations of the Present Study}

- The pain score was measured in response to an electric pulp tester rather than an actual clinical procedure as it was not possible to replicate the clinical procedure at each titration level.

- As the age and dexterity of the patient were variable, the diagrams for the bender motor visual gestalt test could not be uniformly assigned and were chosen by the patient himself.

\section{References}

1. Paterson SA, Tahmassebi JF. Paediatric dentistry in the new millennium: 3. Use of inhalation sedation in paediatric dentistry. Dental Update 2003;30(7):350-356. DOI: 10.12968/denu.2003.30.7.350.

2. Clark M. Handbook Of Nitrous Oxide And Oxygen Sedation. 4th ed. 2014. p.272. Print Book ISBN: 9781455745470.

3. Guideline on Use of Nitrous Oxide for Pediatric Dental Patients, Originating Council American Academy of Pediatr Dent, 2016;37:6-15.

4. Nicholas J, Welie JVM. Current status of nitrous oxide as a behavior management practice routine in pediatric Dentistry. J Dent Child 2011;78:24-30.

5. Samir PV, Namineni S, Sarada P. Assessment of hypoxia, sedation level, and adverse events occurring during inhalation sedation using preadjusted mix of $30 \%$ nitrous oxide $+70 \%$ oxygen. J Indian 
Soc Pedod Prev Dent 2017;35(4):338-345. DOI: 10.4103/JISPPD. JISPPD_15_17.

6. Freeman R, Carson P. Relative analgesia and general dental practitioners: attitudes and intentions to provide conscious sedation for pediatric dental extractions. Int J Pediat Dentist 2003;13(5):320326. DOI: 10.1046/j.1365-263X.2003.00480.x.

7. Dunn RT, Adair SM, Sams DR, et al. Oxygen saturation and diffusion hypoxia in children following nitrous oxide sedation. Pediatr Dent 1993;15:88-92.

8. Trimble T. Sedated Procedures Safely and Effectively - An Emergency Department Outline. [cited 2005]; Available from:URL: www.enw.org/ SedationGuidelines.htm.

9. Kaviani N, Birang R. Evaluation of need to pulse oximetry monitoring during inhalation sedation for periodontal treatments. Dent Res J 2006;3:1-5.

10. Stanley FM, Morris SC. Nitrous oxide-oxygen: a new look at a very old technique. J Calif Dent Association 2003;31:397-403.

11. Houpt MI, Limb R, Livingston RL. Clinical effects of nitrous oxide conscious sedation in children. Pediatr Dent 2004;26:29-36.

12. Vilanova-Saingery C, Bailleul-Forestier I, Vaysse F, et al. Use and perception of nitrous oxide sedation by french dentists in private practice: a national survey. Eur Arch Paediatr Dent 2017;18(6):385-391. DOI: 10.1007/s40368-017-0307-7.

13. http://www.gidsr.com/nitrous-oxide-oxygen-inhalation-conscious. php.

14. Frumin MJ, Edelist G. Diffusion anoxia: a critical reappraisal. Anesth 1969;31(3):243-249. DOI: 10.1097/00000542-196909000-00010.

15. Khinda VI, Bhuria P, Khinda P. Comparative evaluation of diffusion hypoxia and psychomotor skills with or without postsedation oxygenation following administration of nitrous oxide in children undergoing dental procedures: a clinical study. J India Soc Pedod Prev Dent 2016;34(3):217-222. DOI: 10.4103/0970-4388. 186751.

16. Malamed SF. Sedation: a guide to patient management. St Louis. CV Mosby Co; 1989. p. 102.
17. Primosch R, McLellan $M$, Jerrell $G$, et al. Effect of scavenging on the pychomotor and cognitive function of subjects sedated with nitrous oxide and oxygen inhalation. Pediatr Dent 1997;19:480-483.

18. Allison RH, Shirley AW, Smith G. Threshold concentration of nitrous oxide affecting psychomotor performance. $\mathrm{Br} J$ Anaesth 1979;51(3):177-180. DOI: 10.1093/bja/51.3.177.

19. Nathan JE, Venham LL, West MS, et al. The effects of nitrous oxide on anxious young pediatric patients across sequential visits: a doubleblind study. ASDC J Dent Child 1988;55:220-230.

20. Roberts GJ, Gibson A, Porter J, et al. Physiological changes during relative analgesia- a clinical study. J Dent 1982;10(1):55-64. DOI: 10.1016/0300-5712(82)90009-4

21. Howard WR. Nitrous oxide in the dental environment: assessing the risk, reducing the exposure. J Am Dent Assoc 1997;128(3):356-360. DOI: 10.14219/jada.archive.1997.0201.

22. Aeschliman SD, Blue MS, Williams KB, et al. A preliminary study on oxygen saturation levels of patients during periodontal surgery with and without oral conscious sedation using diazepam. J Periodontol 2003;74(7):105. DOI: 10.1902/jop.2003.74.7.1056.

23. Brondani JT, Nataline CC, Pippi NL, et al. Ketamine, midazolam and nitrous oxide anesthesia in dogs submitted to cervical esophagoplasty. Cienc Rural 2003;33(6):1075-1080. DOI: 10.1590/ S0103-84782003000600012.

24. Houpt MI, Sheskin RB, Koenigsberg SR, et al. Assessing chloral hydrate dosage for young children. ASDC J Dent Child 1985;52:364-369.

25. Emmanouil DE, Quock RM. Advances in understanding the actions of nitrous oxide. Anesth Prog 2007;54(1):9-18. DOI: 10.2344/0003-3006(2007)54[9:AIUTAO]2.0.CO;2.

26. Austin ML, Nitrous Oxide Sedation: Clinical Review \& Workplace Safety. The Academy of Dental Learning \& OSHA Training; 2013.

27. Verwest TM, Primosch RE, Courts FJ.Variables influencing hemoglobin oxygen desaturation in children during routine restorative dentistry Pediatr Dent 1993;15:25-29.

28. Ayer WA, Getter L. Psychomotor responses to nitrous oxide-oxygen sedation during dental treatment. Anesth Prog 1974;21:71-73. 